\title{
Survey Analysis of Regional Name, Use and Availability of Echinops setifer at Jeonnam Province
}

\author{
Yun Jum Park', Yang Gyu Ku', Ho Cheol Kim', Bo Ra Hwang', and Buk Gu Heo² * \\ ${ }^{1}$ Department of Horticulture Industry, Wonkwang University, Iksan 54538, South Korea \\ ${ }^{2}$ Naju Foundation of Natural Dyeing Culture, Naju 58280, South Korea
}

\begin{abstract}
In order to establish the succession and development of usage culture of Echinops setifer rice cake, the survey on 282 Women (60 years old or over living in 21 cities and counties in Jeonam province) was investigated. The results showed that all respondents did not know the standard name of Echinops setifer. One hundred and twenty four repondents (54.0\%) knew the regional name of Echinops setifer and regional name was called differently by region. Less than $6.8 \%$ of respondents answered that most recent eating time of Echinops setiferwas since 1980. 58 respondents (20.6\%) had experience making Echinops setifer rice cake. Less than $6.9 \%$ of respondents made Echinops setifer rice cake latest since 1990. The taste and stickiness of Echinops setifer rice cake were evaluated as 'delicious (4.56)' and 'above sticky (4.63)' according to criterion level 5.0. These results suggest that the standard name of Echinops setifer is spread widely and usage culture of Echinops setifer is needed to be developed.
\end{abstract}

Keywords: bunchu, bundae, edible taste, sticy taste, traditional rice cake

\section{Introduction}

Echinops setifer (Jeolgutdae in Korean) is a herbaceous perennial that belongs to the genus of Echinops setifer, family of compositae and order of asterales, originating from Korea and Manchuria in terms of plant geography. The Echinops setifer has been introduced from Korea to Japan during the Quaternary period (Murata, 1977). Echinops, the genus name of Echinops setifer, is a compound of the Greek words echinos (hedgehog) and pos (feet), and the species name setifer means 'having thorny hair.' The scientific name Echinops setifer originates from how the shape of the round hair-shaped inflorescence is like the feet of thorny hedgehog (Kawatani et al., 1967).

The flowers of Echinops setifer are receiving attention as ornamental plants, and its roots are used as medicinal herb named lou lu (radix rhapontici) effective for lowering fever, curing nursing breasts that are running dry, blue heat, alleviating heat, detoxification, healing wounds, treating pleurisy, curing breastfeeding problems, and facilitating blood flow (Heo, 2015). The Ministry of the Environment in Japan has designated Echinops setifer as an endangered species and is studying protective measures (Kaneko et al., 2009; Nakanishi, 2010; Sugimura, 2002), and garden cultivars for flowering are developed and distributed in Europe.

This paper is supported by the Wonkwang University research grants in 2017.

Received: November 23, 2017, Revised: December 11, 2017, Accepted: December 12, 2017

*Comesponding author: bukgu@naver.com 
Echinops setifer has been widely known as ornamental plant and medicinal herb. There were no cases in which it was distributed as rice cake and edible resource (Bae et al., 2005; Cho et al., 2005; Cho et al., 2007; Im et al., 2011; Oh et al., 2010; Park and Chun, 2015). Even surveys on traditional rice cake did not show any report about how it was used as a source of rice cake (Kim et al., 2012; Kim et al., 2014; Won et al., 2008). However, Heo (2015) discovered that the plant used in bunchu rice cake, which was known to be the most delicious and stickiest rice cake in Naju in the past. It was also used as an excellent rice cake resource in Jeongeup and Jeonbuk (Cho et al., 2017a, b). Echinops setifer has traditionally been used as an edible resource plant in some regions and thus has developed the value of usage and the cultural aspect of the plant. However, there is almost no specific research on regional name and use method of Echinops setifer.

Therefore, this study was conducted to examine the regional name, use and availability of Echinops setifer with a survey on the elderly living in Jeonnam where the culture of using Echinops setifer as a rice cake resource is being passed down.

\section{Research Method}

\section{Survey period, subject and region}

The survey for this study was conducted from January 2015 to the end of December 2016. The subjects were the elderly

Table 1. Number and percent of the respondents by province and age.

\begin{tabular}{|c|c|c|c|c|c|}
\hline \multirow{2}{*}{ Region } & \multicolumn{4}{|c|}{ Number of respondents by age (\%) } & \multirow{2}{*}{ Total $(\%)$} \\
\hline & Sixties & Seventies & Eighties & Nineties & \\
\hline Gangjin & $3(23.1)^{z}$ & $2(15.4)$ & $5(38.5)$ & $3(23.1)$ & $13(100)$ \\
\hline Goheung & $5(31.3)$ & $4(25.0)$ & $5(31.3)$ & $2(12.5)$ & $16(100)$ \\
\hline Gokseong & $4(36.4)$ & $4(36.4)$ & $2(18.2)$ & $1(9.1)$ & $11(100)$ \\
\hline Gwangyang & $3(20.0)$ & $4(26.7)$ & $5(33.3)$ & $3(20.0)$ & $15(100)$ \\
\hline Gurye & $4(30.8)$ & $5(38.5)$ & $3(23.1)$ & $1(7.7)$ & $13(100)$ \\
\hline Naju & $3(14.3)$ & $6(28.6)$ & $8(38.1)$ & $4(19.0)$ & $21(100)$ \\
\hline Damyang & $3(21.4)$ & $7(50.0)$ & $4(28.6)$ & $0(0.0)$ & $14(100)$ \\
\hline Muan & $4(33.3)$ & $3(25.0)$ & $3(25.0)$ & $2(16.7)$ & $12(100)$ \\
\hline Boseong & $4(30.8)$ & $5(38.5)$ & $4(30.8)$ & $0(0.0)$ & $13(100)$ \\
\hline Suncheon & $3(21.4)$ & $4(28.6)$ & $6(42.9)$ & $1(7.1)$ & $14(100)$ \\
\hline Sinan & $3(27.3)$ & $3(27.3)$ & $4(36.4)$ & $1(9.1)$ & $11(100)$ \\
\hline Yeosu & $4(28.6)$ & $5(35.7)$ & $3(21.4)$ & $2(14.3)$ & $14(100)$ \\
\hline Yeonggwang & $4(20.0)$ & $9(45.0)$ & $7(35.0)$ & $0(0.0)$ & $20(100)$ \\
\hline Yeongam & $3(25.0)$ & $4(33.3)$ & $3(25.0)$ & $2(16.7)$ & $12(100)$ \\
\hline Wando & $4(33.3)$ & $3(25.0)$ & $4(33.3)$ & $1(8.3)$ & $12(100)$ \\
\hline Jangseong & $3(30.0)$ & $2(20.0)$ & $3(30.0)$ & $2(20.0)$ & $10(100)$ \\
\hline Jangheung & $3(25.0)$ & $1(8.3)$ & $3(25.0)$ & $5(41.7)$ & $12(100)$ \\
\hline Jindo & $3(23.1)$ & $3(23.1)$ & $4(30.8)$ & $3(23.1)$ & $13(100)$ \\
\hline Hampyeong & $2(22.2)$ & $3(33.3)$ & $2(22.2)$ & $2(22.2)$ & $9(100)$ \\
\hline Haenam & $6(50.0)$ & $2(16.7)$ & $4(33.3)$ & $0(0.0)$ & $12(100)$ \\
\hline Hwasun & $3(20.0)$ & $3(20.0)$ & $7(46.7)$ & $2(13.3)$ & $15(100)$ \\
\hline Total & $74(26.2)$ & $82(29.1)$ & $89(31.6)$ & $37(13.1)$ & $282(100.0)$ \\
\hline
\end{tabular}

${ }^{\mathrm{z}}$ Percent $=$ number of respondents by age / total number of respondents X 100 . 
women aged 60 or over (as of the end of 2016) living in 21 cities and counties of Jeonnam province, with total 282 respondents including 74 in their 60s (26.2\%), 82 in their 70s (29.1\%), 89 in their 80s (31.6\%), and 37 in their 90s (13.1\%) (Table 1). The survey was conducted by visiting 21 cities and counties in Jeonnam: Seongjeon-myeon in Gangjin, Donggang-myeon in Goheung, Gokseong-eup and Gyeom-myeon in Gokseong, Bonggang-myeon in Gwangyang, Gurye-eup and Yongbang-myeon in Gurye, Dasi-myeon, Munpyeong-myeon, Dado-myeon and Seji-myeon in Naju, Damyang-eup and Mujeong-myeon in Damyang, Illo-eup and Mongtan-myeon in Muan, Mundeok-myeon, Boknaemyeon and Beolgyo-eup in Boseong, Juam-myeon in Suncheon, Aphae-myeon in Sinan, Cheongsan 2-gu in Yeosu, Gunnam-myeon and Bulgap-myeon in Yeonggwang, Geumjeong-myeon in Yeongam, Noam-myeon and Bogil-myeon in Wando, Samseo-myeon in Jangseong, Gwansan-eup and Hoejin-myeon in Jangheung, Gogun-myeon and Gunnae-myeon in Jindo, Nasan-myeon in Hampyeong, Gyegok-myeon and Munnae-myeon in Haenam, and Dong-myeon and Dongbok-myeon in Hwasun.

\section{Survey method}

The preliminary survey showed that Echinops setifer was called in different names according to the region and thus communication would be impossible by Echinops setifer name only. Thus, as shown in Fig. 1, photos of Echinops setifer were printed in color and shown to the subjects while they were asked about each item of the questionnaire. The responses were directly marked on the questionnaire prepared by the researchers.

\section{Survey items and content}

\section{Regional name and the number of name of Echinops setifer}

Photos of Echinops setifer (Fig. 1) were presented to the respondents, and they were asked whether they know the plant's existence and plant name, and the relevant names were recorded. In this process, two or less than two people of total respondents were classified as 'others.' The redundant responses were included 124 out of total 282 respondents, excluding 158 (56.0\%) respondents who did not know the existence of Echinops setifer. The number of Echinops setifer name was first surveyed and the relevant number of respondents was calculated to convert it into a percentage.

\section{Experience and the latest experience of eating rice cake of Echinops setifer}

To determine the experience of eating rice cake of Echinops setifer, the age of respondents were classified into 60s, 70s, $80 \mathrm{~s}$ and $90 \mathrm{~s}$, and the percentage of respondents regarding experience of eating (\%) was calculated by 'number of
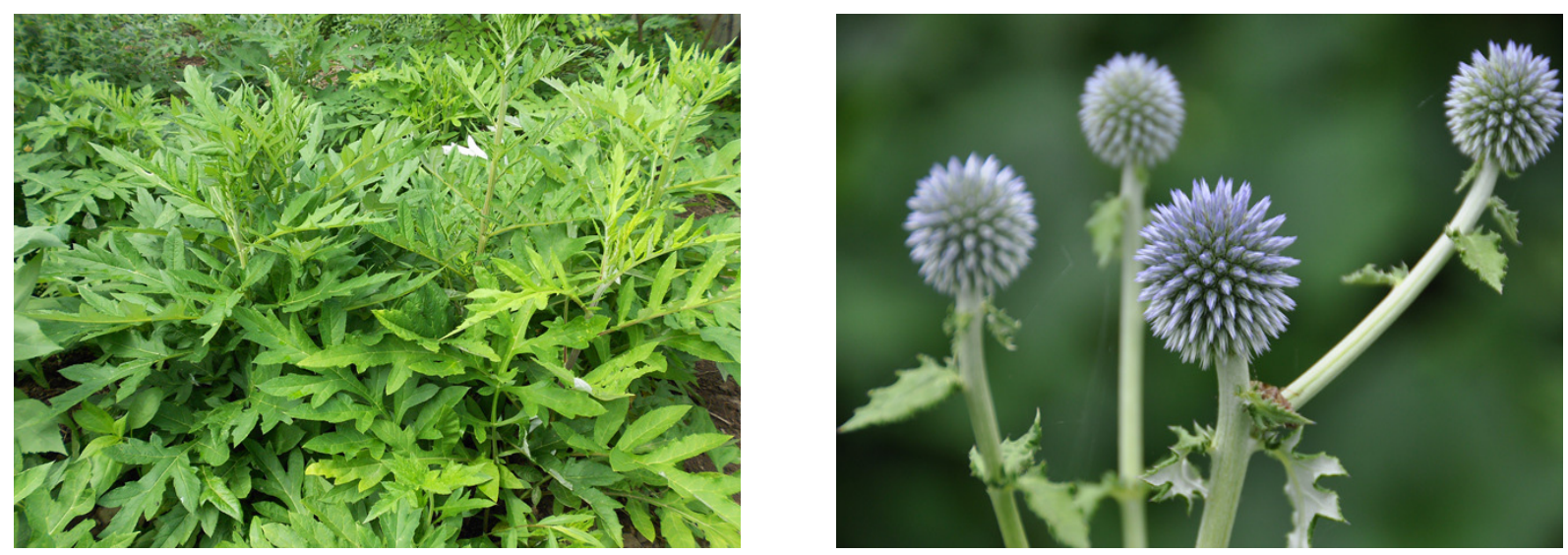

Figure 1. Photos of Echinops setifer used in this research. 
responses / number of respondents X 100.' The most recent time they ate the rice cake was determined by asking the relevant question to 103 respondents of eating experience of Echinops setifer rice cake, and then classifying the responses into before 1960,1960s, 1970s, 1980s, 1990s, 2000s, and after 2010 to calculate the percentage of each.

\section{Experience and the latest experience of making rice cake of Echinops setifer}

To determine the experience of making rice cake with Echinops setifer, the respondents were to freely talk about the types of rice cake they made with Echinops setifer and the percentage of respondents was calculated regarding experience of making (\%) by 'number of responses / number of respondents X 100.' The most recent time they made the rice cake was determined by asking the relevant question to 58 respondents with eating experience of Echinops setifer rice cake, and then classifying the responses into before 1960,1960s, 1970s, 1980s, 1990s, 2000s, and after 2010 to calculate the percentage of each.

\section{Taste and stickiness of rice cake of Echinops setifer}

Taste and stickiness of rice cake of Echinops setifer were rated on a 5-point scale by 103 respondents with eating experience of Echinops setifer rice cake. The researchers asked them about the taste and gave 5 points to very tasty, 4 points to tasty, 3 points to average, 2 points to not tasty, and 1 point to not tasty at all. For stickiness, 5 points were given to very sticky, 4 points to sticky, 3 points to average, 2 points to not sticky, and 1 point to not sticky at all. The results were added up to calculate the average.

\section{Data collection and analysis}

The collected data was categorized and coded into an Excel file. SPSS 12.0 for Windows was used for frequency analysis and Pearson's chi-squared test $\left(\chi^{2}\right)$ for cross-tabulation analysis.

\section{Results and Discussions}

\section{Regional name and the number of name of Echinops setifer}

As a result of surveying 282 women aged 60 or over living in 21 cities and counties of Jeonnam regarding the names of Echinops setifer, it was found that not a single one of them was aware of the standard name Jeolgutdae, but 124 (44.0\%) respondents knew the regional name of Echinops setifer (Table 2). The ratio of bundae (25.2\%)>bunchu (16.0\%) was high including redundant responses, followed by those above $2.1 \%$ such as gasibundae $(3.9 \%)$, buchu (2.8\%), gasaebunchu (2.8\%), beonchu (2.5\%), and sseoraebunchu (2.1\%), as well as other names such as kalbundae, topbundae, beonhochu, and sutbunchu.

By region, it was discovered that the names bundae and bunchu were used in 10 regions. Bundae was used only in Gokseong, Damyang, Yeonggwang, and Hwasun, while bunchu was used only in Gangjin, Gurye, Muan, and Jangheung. Both bundae and bunchu were used in Naju, Boseong, Suncheon, Yeongam, Jangseong, and Hampyeong. The most commonly used name by region was beonchu in Gangjin (26.9\%), bundae in Gokseong (35.7\%), buchu in Gurye (25.0\%), beonhochu (50.0\%), and gasaebunchu (6.5\%) and sseoraebunchu (6.5\%) in Haenam, showing regional differences. This result is similar to Gnaphalium affine that is called by different regional names by region instead of standard name while being used as an ingredient for rice cake in Jeonnam like Echinops setifer (Park et al., 2017). Furthermore, this was similar to the study by Cho et al. (2017b) surveying 119 women aged 60 or over in Jeongeup, Jeonbuk regarding the awareness of 
Table 2. Regional name of Echinops setifer known to women aged 60 or over living in Jeonnam province.

\begin{tabular}{|c|c|c|c|c|c|c|c|c|c|}
\hline \multirow{2}{*}{ Region } & \multicolumn{9}{|c|}{ Respondents in percent by regional name (n) } \\
\hline & Bundae & Bunchu & Beonchu & Buchu & Gasibundae & Gasaebunchu & Sseroraebunchu & Other & Unknown \\
\hline Gangjin & $0.0^{z}(0)^{y}$ & $19.2(5)$ & $26.9(7)$ & $0.0(0)$ & $0.0(0)$ & $11.5(3)$ & 19.2(5) & $11.5(3)$ & $11.5(3)$ \\
\hline Goheung & $0.0(0)$ & $0.0(0)$ & $0.0(0)$ & $0.0(0)$ & $0.0(0)$ & $0.0(0)$ & $0.0(0)$ & $0.0(0)$ & $100.0(16)$ \\
\hline Gokseong & $35.7(5)$ & $0.0(0)$ & $0.0(0)$ & $0.0(0)$ & $0.0(0)$ & $0.0(0)$ & $0.0(0)$ & $21.4(3)$ & $42.9(6)$ \\
\hline Gwangyang & $0.0(0)$ & $0.0(0)$ & $0.0(0)$ & $0.0(0)$ & $0.0(0)$ & $0.0(0)$ & $0.0(0)$ & $0.0(0)$ & $100.0(15)$ \\
\hline Gurye & $0.0(0)$ & $20.0(4)$ & $0.0(0)$ & $25.0(5)$ & $0.0(0)$ & $0.0(0)$ & $0.0(0)$ & $15.0(3)$ & $40.0(8)$ \\
\hline Naju & $22.6(7)$ & $25.8(8)$ & $0.0(0)$ & $0.0(0)$ & $3.2(1)$ & $6.5(2)$ & $0.0(0)$ & $19.4(6)$ & $22.6(7)$ \\
\hline Damyang & $58.8(10)$ & $0.0(0)$ & $0.0(0)$ & $0.0(0)$ & $0.0(0)$ & $0.0(0)$ & $0.0(0)$ & $17.6(3)$ & $23.5(4)$ \\
\hline Muan & $0.0(0)$ & $41.7(5)$ & $0.0(0)$ & $0.0(0)$ & $0.0(0)$ & $0.0(0)$ & $0.0(0)$ & $0.0(0)$ & $58.3(7)$ \\
\hline Boseong & $7.7(1)$ & 23.1(3) & $0.0(0)$ & 23.1(3) & $0.0(0)$ & $0.0(0)$ & $0.0(0)$ & $0.0(0)$ & $46.2(6)$ \\
\hline Suncheon & $41.2(7)$ & $5.9(1)$ & $0.0(0)$ & $0.0(0)$ & $11.8(2)$ & $0.0(0)$ & $0.0(0)$ & $0.0(0)$ & $41.2(7)$ \\
\hline Sinan & $0.0(0)$ & $0.0(0)$ & $0.0(0)$ & $0.0(0)$ & $0.0(0)$ & $0.0(0)$ & $0.0(0)$ & $0.0(0)$ & $100.0(11)$ \\
\hline Yeosu & $0.0(0)$ & $0.0(0)$ & $0.0(0)$ & $0.0(0)$ & $0.0(0)$ & $0.0(0)$ & $0.0(0)$ & $0.0(0)$ & $100.0(14)$ \\
\hline Yeonggwang & $75.0(15)$ & $0.0(0)$ & $0.0(0)$ & $0.0(0)$ & $0.0(0)$ & $0.0(0)$ & $0.0(0)$ & $0.0(0)$ & $25.0(5)$ \\
\hline Yeongam & $41.2(7)$ & $41.2(7)$ & $0.0(0)$ & $0.0(0)$ & $0.0(0)$ & $0.0(0)$ & $0.0(0)$ & $0.0(0)$ & $17.6(3)$ \\
\hline Wando & $0.0(0)$ & $0.0(0)$ & $0.0(0)$ & $0.0(0)$ & $0.0(0)$ & $0.0(0)$ & $0.0(0)$ & $0.0(0)$ & $100.0(12)$ \\
\hline Jangseong & $33.3(5)$ & $13.3(2)$ & $0.0(0)$ & $0.0(0)$ & $26.7(4)$ & $0.0(0)$ & $0.0(0)$ & $6.7(1)$ & $20.0(3)$ \\
\hline Jangheung & $0.0(0)$ & $31.3(5)$ & $0.0(0)$ & $0.0(0)$ & $0.0(0)$ & $12.5(2)$ & $0.0(0)$ & $25.0(4)$ & $31.3(5)$ \\
\hline Jindo & $0.0(0)$ & $0.0(0)$ & $0.0(0)$ & $0.0(0)$ & $0.0(0)$ & $0.0(0)$ & $0.0(0)$ & $0.0(0)$ & $100.0(13)$ \\
\hline Hampyeong & $8.3(1)$ & $41.7(5)$ & $0.0(0)$ & $0.0(0)$ & $0.0(0)$ & $0.0(0)$ & $0.0(0)$ & $25.0(3)$ & $25.0(3)$ \\
\hline Haenam & $0.0(0)$ & $0.0(0)$ & $0.0(0)$ & $0.0(0)$ & $0.0(0)$ & $6.3(1)$ & $6.3(1)$ & $37.5(6)$ & $50.0(8)$ \\
\hline Hwasun & $68.4(13)$ & $0.0(0)$ & $0.0(0)$ & $0.0(0)$ & 21.1(4) & $0.0(0)$ & $0.0(0)$ & $0.0(0)$ & $10.5(2)$ \\
\hline Total & $25.2(71)$ & $16.0(45)$ & $2.5(7)$ & $2.8(8)$ & $3.9(11)$ & $2.8(8)$ & $2.1(6)$ & $8.9(25)$ & $56.0(158)$ \\
\hline
\end{tabular}

${ }^{\mathrm{z}}$ Percent $=$ number of each response $/$ total number of responses in the region (including the duplicated responses) X 100.

${ }^{\mathrm{y}}$ Number of respondent.

Echinops setifer names, that 95 (79.8\%) respondents knew about Echinops setifer but none of them knew the standard name. Therefore, it seems necessary to know the standard name along with a general survey in terms of succession and development of traditional rice cake resource plant.

As a result of surveying 124 out of 282 women aged 60 or over living in 21 cities and counties of Jeonnam who also responded that they were aware of Echinops setifer, 26.3\% respondents knew one name of Echinops setifer, 15.2\% respondents knew 2 names of Echinops setifer, and 2.5\% respondents knew 3 names of Echinops setifer (Table 3). This indicates that Echinops setifer name was called a few regional names in different regions. Compared to the study by Cho et al. (2017b), $79.8 \%$ of 95 respondents knew the plant name as gasaebundae, $12.6 \%$ as gasibundae and $0.8 \%$ as ssoegibundae, the regional names for Echinops setifer showed great regional gaps. Therefore, it is necessary to be well aware of the regional names to survey the usage culture of Echinops setifer among the elderly, and to provide a standard name in order to pass down and develop the traditional culture of using Echinops setifer. 
Table 3. A number of names of $E$. Setifer known to women aged 60 or over living in Jeonnam province.

\begin{tabular}{|c|c|c|c|c|c|}
\hline \multirow{2}{*}{ Region } & \multicolumn{5}{|c|}{ Respondents in percent by a number of names of E. Setifer (n) } \\
\hline & Zero & One & Two & Three & Total \\
\hline Gangjin & $23.1^{\mathrm{z}}(3)^{\mathrm{y}}$ & 23.1(3) & $38.5(5)$ & $15.3(2)$ & $100(13)$ \\
\hline Goheung & $100.0(16)$ & $0.0(0)$ & $0.0(0)$ & $0.0(0)$ & $100(16)$ \\
\hline Gokseong & $54.5(6)$ & $18.2(2)$ & 27.3(3) & $0.0(0)$ & $100(11)$ \\
\hline Gwangyang & $100.0(15)$ & $0.0(0)$ & $0.0(0)$ & $0.0(0)$ & $100(15)$ \\
\hline Gurye & $61.5(8)$ & $7.7(1)$ & $7.7(1)$ & 23.1(3) & $100(13)$ \\
\hline Naju & $33.3(7)$ & $23.8(5)$ & $38.1(8)$ & $4.8(1)$ & $100(21)$ \\
\hline Damyang & $28.6(4)$ & $50.0(7)$ & 21.4(3) & $0.0(0)$ & $100(14)$ \\
\hline Muan & $58.3(7)$ & $41.7(5)$ & $0.0(0)$ & $0.0(0)$ & $100(12)$ \\
\hline Boseong & $46.2(6)$ & $53.8(7)$ & $0.0(0)$ & $0.0(0)$ & $100(13)$ \\
\hline Suncheon & $50.0(7)$ & $35.8(5)$ & $7.1(1)$ & $7.1(1)$ & $100(14)$ \\
\hline Sinan & $100.0(11)$ & $0.0(0)$ & $0.0(0)$ & $0.0(0)$ & $100(11)$ \\
\hline Yeosu & $100.0(14)$ & $0.0(0)$ & $0.0(0)$ & $0.0(0)$ & $100(14)$ \\
\hline Yeonggwang & $25.0(5)$ & $75.0(15)$ & $0.0(0)$ & $0.0(0)$ & $100(20)$ \\
\hline Yeongam & $25.0(3)$ & $33.3(4)$ & $41.7(5)$ & $0.0(0)$ & $100(12)$ \\
\hline Wando & $100.0(12)$ & $0.0(0)$ & $0.0(0)$ & $0.0(0)$ & $100(12)$ \\
\hline Jangseong & $30.0(3)$ & $30.0(3)$ & $40.0(4)$ & $0.0(0)$ & $100(10)$ \\
\hline Jangheung & $41.7(5)$ & $33.3(4)$ & $25.0(3)$ & $0.0(0)$ & $100(12)$ \\
\hline Jindo & $100.0(13)$ & $0.0(0)$ & $0.0(0)$ & $0.0(0)$ & $100(13)$ \\
\hline Hampyeong & $33.3(3)$ & $33.3(3)$ & $33.3(3)$ & $0.0(0)$ & $100(9)$ \\
\hline Haenam & $66.7(8)$ & $8.3(1)$ & $25.0(3)$ & $0.0(0)$ & $100(12)$ \\
\hline Hwasun & $13.3(2)$ & $60.0(9)$ & $26.7(4)$ & $0.0(0)$ & $100(15)$ \\
\hline Total & $56.0^{\mathrm{x}}(158)$ & $26.3(74)$ & $15.2(43)$ & $2.5(7)$ & $100(282)$ \\
\hline
\end{tabular}

${ }^{\mathrm{z}}$ Percent $=$ number of each respondents $/$ total number of respondents in the region $\mathrm{X} 100$.

${ }^{\mathrm{y}}$ Number of respondent.

${ }^{\mathrm{x}}$ Percent $=$ total number of respondents in regional name / total number of respondents ( 282 women) X 100.

${ }^{\mathrm{w}}$ Chi square analysis: Chi square value (**; significance at $1 \%$ levels).

\section{Experience and the latest experience of eating Echinops setifer rice cake}

As a result of surveying 282 women aged 60 or over living in 21 cities and counties of Jeonnam to determine the experience of eating Echinops setifer by use, all of them with experience responded that they used it only in rice cake, and only $36.5 \%$ (103) of the respondents had eating experience of Echinops setifer rice cake (Table 4). There were regional differences in the ratio of responses that they ate rice cake. At least $58 \%$ respondents had eating experience of Echinops setifer rice cake such as Gangjin (76.9\%), Naju (71.4\%), Yeonggwang (65.0\%), Jangseong (70.0\%), Hampyeong (66.7\%), Hwasun (60.0\%), Yeongam (58.3\%) and Jangheung (58.3\%), but $0 \%$ in Goheung, Gwangyang, Sinan, Yeosu, Wando, and Jindo.

Plant ingredients that have been used in traditional Korean rice cake are well introduced in Gyuhapchongseo and Chosunmusangsinsikyorijebub, both of which also do not mention Echinops setifer (Kim et al., 2012; Kim et al., 2014). 
Unlike the absence of the plant in a study on ingredients used in traditional rice cake (Won et al., 2008), this study revealed from a survey on the elderly that Echinops setifer is used as an ingredient of rice cake. Therefore, it is necessary to conduct an extensive research about the culture of using native plants among the elderly, implying that there is a possibility where other various native plants aside from Echinops setifer might not have been recorded and passed down even though they are used as rice cake resource plants.

As for experience of eating Echinops setifer rice cake by age, $1.4 \%$ in their $60 \mathrm{~s}, 37.8 \%$, in their $70 \mathrm{~s}, 53.9 \%$ in their $80 \mathrm{~s}$ and $62.1 \%$ in their $90 \mathrm{~s}$ responded that they have experience, showing that the ratio was high among older age groups. By region, Naju was the only place where respondents in their 60 s as well as $83.3 \%$ in their 70 s said they have experience eating Echinops setifer rice cake, indicating that the culture remains relatively more than other regions. On the other hand,

Table 4. Eating experience of Echinops setifer rice cake in women aged 60 or over living in Jeonnam province.

\begin{tabular}{|c|c|c|c|c|c|}
\hline \multirow{2}{*}{ Region } & \multicolumn{5}{|c|}{ Respondents in percent by age (n) } \\
\hline & Sixties & Seventies & Eighties & Nineties & Total \\
\hline Gangjin & $0.0^{\mathrm{z}}(0)^{\mathrm{y}}$ & $100(2)$ & $100(5)$ & $100(3)$ & $76.9(10)$ \\
\hline Goheung & $0.0(0)$ & $0.0(0)$ & $0.0(0)$ & $0.0(0)$ & $0.0(0)$ \\
\hline Gokseong & $0.0(0)$ & $75.0(3)$ & $100.0(2)$ & $0.0(0)$ & $45.5(5)$ \\
\hline Gwangyang & $0.0(0)$ & $0.0(0)$ & $0.0(0)$ & $0.0(0)$ & $0.0(0)$ \\
\hline Gurye & $0.0(0)$ & $20.0(1)$ & $66.7(2)$ & $100.0(1)$ & $30.8(4)$ \\
\hline Naju & $33.3(1)$ & $83.3(5)$ & $75.0(6)$ & $75.0(3)$ & $71.4(15)$ \\
\hline Damyang & $0.0(0)$ & $42.9(3)$ & $50.0(2)$ & - & $35.7(5)$ \\
\hline Muan & $0.0(0)$ & $0.0(0)$ & $100.0(3)$ & 100.0 & $41.7(5)$ \\
\hline Boseong & $0.0(0)$ & $20.0(1)$ & $0.0(0)$ & - & $7.7(1)$ \\
\hline Suncheon & $0.0(0)$ & $25.0(1)$ & $50.0(3)$ & $100.0(1)$ & $35.7(5)$ \\
\hline Sinan & $0.0(0)$ & $0.0(0)$ & $0.0(0)$ & $0.0(0)$ & $0.0(0)$ \\
\hline Yeosu & $0.0(0)$ & $0.0(0)$ & $0.0(0)$ & $0.0(0)$ & $0.0(0)$ \\
\hline Yeonggwang & $0.0(0)$ & $66.7(6)$ & $100.0(7)$ & - & $65.0(13)$ \\
\hline Yeongam & $0.0(0)$ & $50.0(2)$ & $100.0(3)$ & $100.0(2)$ & $58.3(7)$ \\
\hline Wando & $0.0(0)$ & $0.0(0)$ & $0.0(0)$ & $0.0(0)$ & $0.0(0)$ \\
\hline Jangseong & $0.0(0)$ & $100.0(2)$ & $100.0(3)$ & $100.0(2)$ & $70.0(7)$ \\
\hline Jangheung & $0.0(0)$ & $0.0(0)$ & $66.7(2)$ & $100.0(5)$ & $58.3(7)$ \\
\hline Jindo & $0.0(0)$ & $0.0(0)$ & $0.0(0)$ & $0.0(0)$ & $0.0(0)$ \\
\hline Hampyeong & $0.0(0)$ & $66.7(2)$ & $100.0(2)$ & $100.0(2)$ & $66.7(6)$ \\
\hline Haenam & $0.0(0)$ & $50.0(1)$ & $75.0(3)$ & - & $33.3(4)$ \\
\hline Hwasun & $0.0(0)$ & $66.7(2)$ & $71.4(5)$ & $100.0(2)$ & $60.0(9)$ \\
\hline Total & $1.4^{\mathrm{x}}(1)$ & $37.8(31)$ & $53.9(48)$ & $62.1(23)$ & $36.5(103)$ \\
\hline Regional differnce $^{w}$ & \multicolumn{5}{|c|}{$\chi^{2}=61.854(* *)$} \\
\hline Age difference $^{w}$ & \multicolumn{5}{|c|}{$\chi^{2}=94.199(* *)$} \\
\hline
\end{tabular}

${ }^{\mathrm{z}}$ Percent $=$ number of respondents with experience $/$ total number of respondents by age and region X 100 .

${ }^{\mathrm{y}}$ Number of respondent.

${ }^{\mathrm{x}}$ Percent $=$ total number of respondents with experience by age / total number of respondents by age X 100 .

${ }^{\mathrm{w}}$ Chi square analysis: Chi square value $(* *$; significance at $1 \%$ levels). 
respondents with eating experience of Echinops setifer rice cake in Jangheung were all in their 80s or older.

Latest experience of eating Echinops setifer was shown in Table 5. The result was shown that the ratio was highest in the order of $1960 \mathrm{~s}(45.6 \%)>$ before $1960(21.4 \%)>1970 \mathrm{~s}(17.5 \%)>1980 \mathrm{~s}(6.8 \%)>1990 \mathrm{~s}(3.9 \%)>2000 \mathrm{~s}(1.9 \%)>$ 2010 s (2.9\%) (Table 5). $2.9 \%$ responded that they ate Echinops setifer rice cake in the 2010s, also since the 1980s the ratio was lower than $6.8 \%$, showing a remarkably low ratio of experience. By region, only Naju and Yeonggwang showed responses after the 2010s. Cho et al. (2017a) surveyed the last time Echinops setifer rice cake was eaten among 119 women aged 60 or over in Jeongup, Jeonbuk and discovered that $2.2 \%$ ate it last after 1991 and $0 \%$ after 2011, showing a similar result with this study. Therefore, it turned out that while there is somewhat a regional difference in the culture of eating Echinops setifer rice cake, most of the culture is declining, which raises the need to study a systematic development and use of Echinops setifer rice cake in terms of use of resource plants and diversification of eating culture.

Table 5. Latest experience of eating rice cake among 107 women aged 60 or over living in Jeonnam province.

\begin{tabular}{|c|c|c|c|c|c|c|c|c|}
\hline \multirow{2}{*}{ Region } & \multicolumn{8}{|c|}{ Respondents in percent by year (n) } \\
\hline & Before 1960 & $1960 \mathrm{~s}$ & $1970 \mathrm{~s}$ & $1980 \mathrm{~s}$ & $1990 \mathrm{~s}$ & $2000 \mathrm{~s}$ & After 2010 & Total \\
\hline Gangjin & $10.0^{\mathrm{z}}(1)^{\mathrm{y}}$ & $90.0(9)$ & $0.0(0)$ & $0.0(0)$ & $0.0(0)$ & $0.0(0)$ & $0.0(0)$ & $100.0(10)$ \\
\hline Goheung & $0.0(0)$ & $0.0(0)$ & $0.0(0)$ & $0.0(0)$ & $0.0(0)$ & $0.0(0)$ & $0.0(0)$ & $0.0(0)$ \\
\hline Gokseong & $0.0(0)$ & $60.0(3)$ & $40.0(2)$ & $0.0(0)$ & $0.0(0)$ & $0.0(0)$ & $0.0(0)$ & $100.0(5)$ \\
\hline Gwangyang & $0.0(0)$ & $0.0(0)$ & $0.0(0)$ & $0.0(0)$ & $0.0(0)$ & $0.0(0)$ & $0.0(0)$ & $0.0(0)$ \\
\hline Gurye & $100.0(4)$ & $0.0(0)$ & $0.0(0)$ & $0.0(0)$ & $0.0(0)$ & $0.0(0)$ & $0.0(0)$ & $100.0(4)$ \\
\hline Naju & $13.3(2)$ & $20.0(3)$ & $20.0(3)$ & $20.0(3)$ & $6.7(1)$ & $6.7(1)$ & $13.3(2)$ & $100.0(15)$ \\
\hline Damyang & $60.0(3)$ & $20.0(1)$ & $0.0(0)$ & $0.0(0)$ & $0.0(0)$ & $20.0(1)$ & $0.0(0)$ & $100.0(5)$ \\
\hline Muan & $60.0(3)$ & $40.0(2)$ & $0.0(0)$ & $0.0(0)$ & $0.0(0)$ & $0.0(0)$ & $0.0(0)$ & $100.0(5)$ \\
\hline Boseong & $100.0(1)$ & $0.0(0)$ & $0.0(0)$ & $0.0(0)$ & $0.0(0)$ & $0.0(0)$ & $0.0(0)$ & $100.0(1)$ \\
\hline Suncheon & $60.0(3)$ & $40.0(2)$ & $0.0(0)$ & $0.0(0)$ & $0.0(0)$ & $0.0(0)$ & $0.0(0)$ & $100.0(5)$ \\
\hline Sinan & $0.0(0)$ & $0.0(0)$ & $0.0(0)$ & $0.0(0)$ & $0.0(0)$ & $0.0(0)$ & $0.0(0)$ & $0.0(0)$ \\
\hline Yeosu & $0.0(0)$ & $0.0(0)$ & $0.0(0)$ & $0.0(0)$ & $0.0(0)$ & $0.0(0)$ & $0.0(0)$ & $0.0(0)$ \\
\hline Yeonggwang & $7.7(1)$ & $53.8(7)$ & $15.4(2)$ & $7.7(1)$ & $7.7(1)$ & $0.0(0)$ & $7.7(1)$ & $100.0(13)$ \\
\hline Yeongam & $14.3(1)$ & $42.8(3)$ & $28.6(2)$ & $14.3(1)$ & $0.0(0)$ & $0.0(0)$ & $0.0(0)$ & $100.0(7)$ \\
\hline Wando & $0.0(0)$ & $0.0(0)$ & $0.0(0)$ & $0.0(0)$ & $0.0(0)$ & $0.0(0)$ & $0.0(0)$ & $0.0(0)$ \\
\hline Jangseong & $14.3(1)$ & $57.1(4)$ & $28.6(2)$ & $0.0(0)$ & $0.0(0)$ & $0.0(0)$ & $0.0(0)$ & $100.0(7)$ \\
\hline Jangheung & $14.3(1)$ & $85.7(6)$ & $0.0(0)$ & $0.0(0)$ & $0.0(0)$ & $0.0(0)$ & $0.0(0)$ & $100.0(7)$ \\
\hline Jindo & $0.0(0)$ & $0.0(0)$ & $0.0(0)$ & $0.0(0)$ & $0.0(0)$ & $0.0(0)$ & $0.0(0)$ & $0.0(0)$ \\
\hline Hampyeong & $0.0(0)$ & $50.0(3)$ & $16.7(1)$ & $0.0(0)$ & $13.3(2)$ & $0.0(0)$ & $0.0(0)$ & $100.0(6)$ \\
\hline Haenam & $0.0(0)$ & $0.0(0)$ & $75.0(3)$ & $25.0(1)$ & $0.0(0)$ & $0.0(0)$ & $0.0(0)$ & $100.0(4)$ \\
\hline Hwasun & 11.1(1) & $44.5(4)$ & $33.3(3)$ & 11.1(1) & $0.0(0)$ & $0.0(0)$ & $0.0(0)$ & $100.0(9)$ \\
\hline Total & $21.4^{\mathrm{x}}(22)$ & $45.6(47)$ & $17.5(18)$ & $6.8(7)$ & $3.9(4)$ & $1.9(2)$ & $2.9(3)$ & $100.0(103)$ \\
\hline Regional difference $^{\mathrm{y}}$ & & & & $\chi^{2}=$ & $(*)$ & & & \\
\hline
\end{tabular}

${ }^{\mathrm{z}}$ Percent $=$ number of respondents with experience / total number of respondents with experience X 100.

${ }^{\mathrm{y}}$ Number of respondent.

${ }^{\mathrm{x}}$ Percent $=$ total number of respondents with experience by year/ total number of respondents with experience (103 women) X 100 .

${ }^{\mathrm{w}}$ Chi square analysis: Chi square value (*; significance at $5 \%$ levels). 


\section{Experience and the latest experience of making Echinops setifer rice cake}

As a result of surveying 282 women aged 60 or over living in 21 cities and counties of Jeonnam regarding the experience of making Echinops setifer rice cake, it was found that only 58 (20.6\%) respondents had experience making Echinops setifer rice cake (Table 6). By region, only respondents living in 12 regions (57.1\%) including Jangheung, Gokseong, and Naju responded that they have experience, and only Hampyeong (55.6\%), Hwasun (53.3\%), Naju (52.4\%), Yeongam (50.0\%), and Jangseong (50.0\%) among them showed at least 50\%, while other regions showed $46.2 \%$. In particular, the ratio of respondents with making experience of the rice cake was $0 \%$ in Goheung, Gwangyang, Gurye, Boseong, Sinan, Yeosu, Wando, and Jindo. By age, $0 \%$ of respondents in their 60 s had experience making Echinops

Table 6. Latest making experience of Echinops setifer rice cake in women aged 60 or over living in Jeonnam province.

\begin{tabular}{|c|c|c|c|c|c|}
\hline \multirow[b]{2}{*}{ Region } & \multicolumn{5}{|c|}{ Respondents in percent by age (n) } \\
\hline & Sixties & Seventies & Eighties & Nineties & $\begin{array}{c}\text { Percent of manufacturing } \\
\text { experience (person) }\end{array}$ \\
\hline Gangjin & $0.0^{\mathrm{z}}(0)^{\mathrm{y}}$ & $0.0(0)$ & $60.0(3)$ & $100.0(3)$ & $46.2(6)$ \\
\hline Goheung & $0.0(0)$ & $0.0(0)$ & $0.0(0)$ & $0.0(0)$ & $0.0(0)$ \\
\hline Gokseong & $0.0(0)$ & $50.0(2)$ & $0.0(0)$ & $0.0(0)$ & $18.2(2)$ \\
\hline Gwangyang & $0.0(0)$ & $0.0(0)$ & $0.0(0)$ & $0.0(0)$ & $0.0(0)$ \\
\hline Gurye & $0.0(0)$ & $0.0(0)$ & $0.0(0)$ & $0.0(0)$ & $0.0(0)$ \\
\hline Naju & $0.0(0)$ & $50.0(3)$ & $75.0(6)$ & $50.0(2)$ & $52.4(11)$ \\
\hline Damyang & $0.0(0)$ & $14.3(1)$ & $0.0(0)$ & - & $7.1(1)$ \\
\hline Muan & $0.0(0)$ & $0.0(0)$ & $0.0(0)$ & $100.0(2)$ & $16.7(2)$ \\
\hline Boseong & $0.0(0)$ & $0.0(0)$ & $0.0(0)$ & - & $0.0(0)$ \\
\hline Suncheon & $0.0(0)$ & $0.0(0)$ & $0.0(0)$ & $100.0(1)$ & 7.1(1) \\
\hline Sinan & $0.0(0)$ & $0.0(0)$ & $0.0(0)$ & $0.0(0)$ & $0.0(0)$ \\
\hline Yeosu & $0.0(0)$ & $0.0(0)$ & $0.0(0)$ & $0.0(0)$ & $0.0(0)$ \\
\hline Yeonggwang & $0.0(0)$ & $22.2(2)$ & $28.6(2)$ & - & $20.0(4)$ \\
\hline Yeongam & $0.0(0)$ & $25.0(1)$ & $100.0(3)$ & $100.0(2)$ & $50.0(6)$ \\
\hline Wando & $0.0(0)$ & $0.0(0)$ & $0.0(0)$ & $0.0(0)$ & $0.0(0)$ \\
\hline Jangseong & $0.0(0)$ & $100.0(2)$ & $33.3(1)$ & $100.0(2)$ & $50.0(5)$ \\
\hline Jangheung & $0.0(0)$ & $0.0(0)$ & $0.0(0)$ & $60.0(3)$ & $25.0(3)$ \\
\hline Jindo & $0.0(0)$ & $0.0(0)$ & $0.0(0)$ & $0.0(0)$ & $0.0(0)$ \\
\hline Hampyeong & $0.0(0)$ & $33.3(1)$ & $100.0(2)$ & $100.0(2)$ & $55.6(5)$ \\
\hline Haenam & $0.0(0)$ & $50.0(1)$ & $75.0(3)$ & - & $33.3(4)$ \\
\hline Hwasun & $0.0(0)$ & $66.7(2)$ & $57.1(4)$ & $100.0(2)$ & $53.3(8)$ \\
\hline Total & $0.0^{\mathrm{x}}(0)$ & $18.3(15)$ & $27.0(24)$ & 51.4(19) & $20.6(58)$ \\
\hline Regional difference $z^{w}$ & \multicolumn{5}{|c|}{$\chi^{2}=75.893(* *)$} \\
\hline Age difference ${ }^{w}$ & \multicolumn{5}{|c|}{$\chi^{2}=45.047(* *)$} \\
\hline
\end{tabular}

${ }^{\mathrm{z}}$ Percent $=$ number of respondents with experience / total number of respondents by age and region $\mathrm{X} 100$.

${ }^{\mathrm{y}}$ Number of respondent.

${ }^{\mathrm{x}}$ Percent $=$ total number of respondents with experience by age / total number of respondents by age X 100 .

${ }^{\mathrm{w}}$ Chi square analysis: Chi square value $(* *$; significance at $1 \%$ levels). 
setifer rice cake, followed by $18.3 \%$ in their $70 \mathrm{~s}, 27.0 \%$ in their $80 \mathrm{~s}$ and $51.4 \%$ in their $90 \mathrm{~s}$, indicating that the ratio was lower among younger age groups. This low ratio of people was shown $0 \%$ of respondents in their 60 s that the skills and culture of making Echinops setifer rice cake would be lost without measures like supplying the rice cake making skills, thereby raising the need to come up with relevant measures.

Latest experience of making Echinops setifer rice cake was shown that the percentage was highest in the order of 1960s $(37.9 \%)>1970 \mathrm{~s}(22.5 \%)>1980 \mathrm{~s}(15.5 \%)>$ before $1960(8.6 \%)>1990 \mathrm{~s}(6.9 \%)>$ after $2000(5.2 \%)>2000 \mathrm{~s}(3.4 \%)$ (Table 7). Among 58 respondents of making experience of Echinops setifer rice cake, but only 4 of them (6.9\%) made it after the 1990s. There were responses that they ate Echinops setifer rice cake in the $2010 \mathrm{~s}$ as well, but the percentage was lower than $6.8 \%$ since the $1980 \mathrm{~s}$. By region, only 3 or less regions had respondents with experience in making rice cake. This result is similar to the study by Cho et al. (2017a), which discovered that among respondents with experience eating

Table 7. Latest experience of making $E$. setifer rice cakes in 58 women aged 60 or over living in Jeonnam province.

\begin{tabular}{|c|c|c|c|c|c|c|c|c|}
\hline \multirow{2}{*}{ Region } & \multicolumn{8}{|c|}{ Respondents in percent by year (n) } \\
\hline & Before 1960 & $1960 \mathrm{~s}$ & $1970 \mathrm{~s}$ & $1980 \mathrm{~s}$ & $1990 \mathrm{~s}$ & $2000 \mathrm{~s}$ & After 2010 & Total \\
\hline Gangjin & $0.0^{\mathrm{z}}(0)^{\mathrm{y}}$ & $100.0(6)$ & $0.0(0)$ & $0.0(0)$ & $0.0(0)$ & $0.0(0)$ & $0.0(0)$ & $100.0(6)$ \\
\hline Goheung & $0.0(0)$ & $0.0(0)$ & $0.0(0)$ & $0.0(0)$ & $0.0(0)$ & $0.0(0)$ & $0.0(0)$ & $0.0(0)$ \\
\hline Gokseong & $0.0(0)$ & $50.0(1)$ & $50.0(1)$ & $0.0(0)$ & $0.0(0)$ & $0.0(0)$ & $0.0(0)$ & $100.0(2)$ \\
\hline Gwangyang & $0.0(0)$ & $0.0(0)$ & $0.0(0)$ & $0.0(0)$ & $0.0(0)$ & $0.0(0)$ & $0.0(0)$ & $0.0(0)$ \\
\hline Gurye & $0.0(0)$ & $0.0(0)$ & $0.0(0)$ & $0.0(0)$ & $0.0(0)$ & $0.0(0)$ & $0.0(0)$ & $0.0(0)$ \\
\hline Naju & $0.0(0)$ & $9.1(1)$ & 27.3(3) & 27.3(3) & $9.1(1)$ & $9.1(1)$ & $18.1(2)$ & $100.0(11)$ \\
\hline Damyang & $0.0(0)$ & $0.0(0)$ & $0.0(0)$ & $0.0(0)$ & $0.0(0)$ & $100.0(1)$ & $0.0(0)$ & $100.0(1)$ \\
\hline Muan & $50.0(1)$ & $50.0(1)$ & $0.0(0)$ & $0.0(0)$ & $0.0(0)$ & $0.0(0)$ & $0.0(0)$ & $100.0(2)$ \\
\hline Boseong & $0.0(0)$ & $0.0(0)$ & $0.0(0)$ & $0.0(0)$ & $0.0(0)$ & $0.0(0)$ & $0.0(0)$ & $0.0(0)$ \\
\hline Suncheon & $100.0(1)$ & $0.0(0)$ & $0.0(0)$ & $0.0(0)$ & $0.0(0)$ & $0.0(0)$ & $0.0(0)$ & $100.0(1)$ \\
\hline Sinan & $0.0(0)$ & $0.0(0)$ & $0.0(0)$ & $0.0(0)$ & $0.0(0)$ & $0.0(0)$ & $0.0(0)$ & $0.0(0)$ \\
\hline Yeosu & $0.0(0)$ & $0.0(0)$ & $0.0(0)$ & $0.0(0)$ & $0.0(0)$ & $0.0(0)$ & $0.0(0)$ & $0.0(0)$ \\
\hline Yeonggwang & $0.0(0)$ & $25.0(1)$ & $0.0(0)$ & $25.0(1)$ & $25.0(1)$ & $0.0(0)$ & $25.0(1)$ & $100.0(4)$ \\
\hline Yeongam & $16.7(1)$ & $33.3(2)$ & $33.3(2)$ & $16.7(1)$ & $0.0(0)$ & $0.0(0)$ & $0.0(0)$ & $100(6)$ \\
\hline Wando & $0.0(0)$ & $0.0(0)$ & $0.0(0)$ & $0.0(0)$ & $0.0(0)$ & $0.0(0)$ & $0.0(0)$ & $0.0(0)$ \\
\hline Jangseong & $0.0(0)$ & $40.0(2)$ & $20.0(1)$ & $40.0(2)$ & $0.0(0)$ & $0.0(0)$ & $0.0(0)$ & $100.0(5)$ \\
\hline Jangheung & $1(33.3)$ & $66.7(2)$ & $0.0(0)$ & $0.0(0)$ & $0.0(0)$ & $0.0(0)$ & $0.0(0)$ & $100.0(3)$ \\
\hline Jindo & $0.0(0)$ & $0.0(0)$ & $0.0(0)$ & $0.0(0)$ & $0.0(0)$ & $0.0(0)$ & $0.0(0)$ & $0.0(0)$ \\
\hline Hampyeong & $0.0(0)$ & $40.0(2)$ & $20.0(1)$ & $0.0(0)$ & $40.0(2)$ & $0.0(0)$ & $0.0(0)$ & $100.0(5)$ \\
\hline Haenam & $0.0(0)$ & $0.0(0)$ & $75.0(3)$ & $25.0(1)$ & $0.0(0)$ & $0.0(0)$ & $0.0(0)$ & $100.0(4)$ \\
\hline Hwasun & $12.5(1)$ & $50.0(4)$ & $25.0(2)$ & $12.5(1)$ & $0.0(0)$ & $0.0(0)$ & $0.0(0)$ & $100.0(8)$ \\
\hline Total & $8.6^{\mathrm{x}}(5)$ & $37.9(22)$ & $22.5(13)$ & $15.5(9)$ & $6.9(4)$ & $3.4(2)$ & $5.2(3)$ & $100.0(58)$ \\
\hline Regional dfference $^{\mathrm{w}}$ & & & & $\chi^{2}=$ & $3(*)$ & & & \\
\hline
\end{tabular}

${ }^{\mathrm{z}}$ Percent $=$ number of respondents with experience $/$ total number of respondents with experience $\mathrm{X} 100$.

${ }^{\mathrm{y}}$ Number of respondent.

${ }^{\mathrm{x}}$ Percent $=$ total number of respondents with experience by year/ total number of respondents with experience (58 women) X 100 .

${ }^{\mathrm{w}}$ Chi square analysis: Chi square value (*; significance at $5 \%$ levels). 
Echinops setifer rice cake among women in their 60 s or over in Jeongup, Jeonbuk, $3.1 \%$ responded that they made the rice cake in 1991-2010 and 0\% since 2011. Therefore, it is necessary to specifically study the culture of using Echinops setifer and to pass it down in terms of use of Echinops setifer and diversification of eating culture.

\section{Evaluation of the taste and stickiness of Echinops setifer rice cake}

Table 7 shows the result of rating the taste and stickiness of Echinops setifer rice cake on a 5-point scale among 103 respondents with experience eating Echinops setifer rice cake out of 282 women aged 60 or over living in 21 cities and counties of Jeonnam. The region was shown the lowest rating for the taste of Echinops setifer rice cake (Gangjin) presented the score of 4.56, which is at least the level of tasty (4.0). In particular, respondents in 10 regions including Gurye and Damyang responded that it is very tasty (5.0), generally reviewing Echinops setifer rice cake as a tasty rice cake. As for stickiness of Echinops setifer rice cake, respondents gave the rating of 4.63 that is at least the level of tasty, and the respondents in 10 regions reviewed it as very tasty (5.0).

As such, considering the study by Cho et al. (2017a) where the taste and stickiness were rated highly regardless of region and the taste and stickiness of Echinops setifer rice cake were rated relatively more highly than rice cake made with other plant ingredients, it can be found that the decline of the culture of making and eating Echinops setifer rice cake was not due to the taste and stickiness of the rice cake. Heo (2015) also stated that the decline of culture of making Echinops

Table 8. Evaluation of the taste and stickiness of Echinops setifer rice cake.

\begin{tabular}{lcc} 
& \multicolumn{2}{c}{ Evaluation value of taste and stickiness } \\
\hline Rangjin & Taste $^{\mathrm{z}}$ & Stickiness $^{\mathrm{y}}$ \\
\cline { 2 - 3 } Gokseong & 4.56 & 4.63 \\
Gurye & 4.80 & 4.80 \\
Naju & 5.00 & 5.00 \\
Damyang & 4.80 & 4.80 \\
Muan & 5.00 & 5.00 \\
Boseong & 5.00 & 5.00 \\
Suncheon & 5.00 & 5.00 \\
Yeonggwang & 5.00 & 5.00 \\
Yeongam & 4.77 & 4.69 \\
Jangseong & 5.00 & 5.00 \\
Jangheung & 5.00 & 5.00 \\
Hampyeong & 5.00 & 5.00 \\
Haenam & 5.00 & 5.00 \\
Hwasun & 5.00 & 5.00 \\
Regional difference & 4.89 & 4.89 \\
\hline
\end{tabular}

${ }^{\mathrm{z}} 5$; Very delicious, 4 ; delicious, 3 ; usually, 2 ; no taste, 1 ; not very tasty.

'5; Very sticky, 4; sticky, 3; usually, 2; no sticky; 1 ; not very sticky.

${ }^{\mathrm{x}}$ Chi square analysis: Chi square value ( ${ }^{\mathrm{NS}}$; non significance at $5 \%$ evels). 
setifer rice cake is mainly caused by the fact that it has become difficult to collect Echinops setifer in wild state. Therefore, there must be follow-up research on the propagation, cultivation and ingredient analysis of Echinops setifer in terms of succession of traditional culture and diversity of eating culture.

\section{Conclusion}

To obtain basic data for the succession and development of the culture of using the native plant Echinops setifer, this study conducted a survey on the regional name and eating culture of 282 women aged 60 and above living in 21 cities and counties of Jeonnam. There was no respondent aware of the standard name of Echinops setifer, and 54.0\% (124) knew regional names. The highest ratio of response for regional names was in the following order, including redundant responses: bundae $(25.2 \%)>$ bunchu $(16.0 \%)>$ buchu $(2.8 \%)$ and gasaebunchu $(2.8 \%) .36 .5 \%$ (103) of respondents have experienced eating rice cake of Echinops setifer, and less than $6.8 \%$ respondents were eaten Echinops setifer rice cake after 1980s. 20.6\% (58) have experienced making Echinops setifer rice cake, and less than $6.9 \%$ respondents were made Echinops setifer rice cake after 1990s. The respondents with eating experience of Echinops setifer rice cake determined the taste and stickiness of the rice cake on a 5-point scale, and they rated it as the level of tasty at the least (4.56) and sticky at the least (4.63). Considering these results, it seems highly necessary to spread the standard name of Echinops setifer and promote the culture of use.

\section{References}

Bae, J.H., T.Y. Cho, S.Y. Yong, B.W. Kim, H.G. Jang, S.U. Chon, and B.G. Heo. 2005. The actual distributing states of the fresh wild vegetables in the five-day traditional markets of the southern districts in Korea. Korean J. Community Living Sci. 16(3):17-24.

Cho, J.Y., S.Y. Yang, S.O. Yu, B.W. Kim, H.G. Jang, S.U. Chon, Y.J. Park, and B.G. Heo. 2005. The actual distributing states of the fresh wild vegetables at five-day traditional markets in Jeonnam district. Korean J. Horti. Sci. Technol. 23(4):396-401.

Cho, J.Y., Y.S. Kim, Y.J. Park, Y.G. Ku, and B.G. Heo. 2017a. The survey of consciousness for women over sixties dwelling in Jeongeup districts on the classified edibility, manufacturing experience and taste of Tteok containing wild plants. J. Korean Soc. Ind Food Technol. 21(1):22-31.

Cho, J.Y., Y.S. Kim, Y.J. Park, Y.G. Ku, and B.G. Heo. 2017b. The survey of women over sixties dwelling in Jeongeup districts on the kinds of Tteok containing wild plants. J. Korean Soc. Ind. Food Technol. 21(1):42-51.

Cho, J.Y., Y.S. Park, S.N. Kwack, M.H. Im, M.K. Lee, and B.G. Heo. 2007. Actual distributing states of the fresh wild vegetables at five-day traditional markets in Gangwon and Jeonnam districts. Korean J. Food Preserv. 14(6):716-721

Heo, B.G. 2015. Naju's Traditional Rice Cakes Made from Echinops setifer. Seo \& Ijae Publishing Co., Kwangju, Korea.

Im, H.T., H.H Hong, H.D. Son, M.S. Park, B.M. Nam, B.K. Kwon, C.H. Lee, and G.Y. Chung. 2011. The usage of regional folk plants in Gyeongsangnam-do. Korean J. Plant Resour. 24(4):419-429.

Kaneko, S., S. Sei, Y. Takahashi, and Y. Isagi. 2009. The current status of Echinops setifer Iljin (Asteraceae) on Aso Mountain and Chugoku Mountain regions. Japanese J. Conserv. Ecol. 14(1):125-130.

Kawatani T., T. Ono, and A. Kanematsu. 1967. Trial cultivation of Echinops setifer Iljin and the isolation of echinopsine. Eisei Shikenjo Hokoku 85:48-55.

Kim, J.H., H.C. Lim, and W.K. Oh. 2014. A literature review investigation collecting and cooking methods of Tteok (Korea rice cake) in 'Chosunmusangsinsikyorijebub'. Food Serv. Ind. J. 10(4):55-67.

Kim, J.H., H.J. Jeong, and W.K. Oh. 2012. A literature review investigati gation collecting and cooking methods of Tteok 
(rice cake) in 'Gyuhapchongseo'. Korean J. Food Nutr. 25(4):1061-1067. DOI:10.9799/ksfan.2012.25.4.1061.

Murata, G. 1977. Phytogeographical consideration on the flora and vegetation of Japan. Acta Phytotaxon. Geobot. 28(1-3): 65-83. DOI:10.18942/bunruichiri.KJ00003217442.

Nakanishi, H. 2010. Distribution and ecology of islet biased plants in northern Kyushu, Japan. Veg. Sci. 27:1-9. DOI:10.15031/vegsci.27.1.

Oh, D.M., J.S. Park, Y.J. Park, J.Y. Cho, S.M. Park, and B.G. Heo. 2010. The actual marketing states of the wild vegetable resources in five-day traditional markets of Gwangyang districts. People Plants Environ. 13(4):83-92.

Park, M.S. and Y.M. Chun. 2015. The usage of regional folk plants in Jeollanam-do. Korean J. Plant Resour. 28(1):79-92. DOI:10.7732/kjpr.2015.28.1.079.

Park, Y.J., Y.G. Ku, H.C. Kim, J.Y. Cho, and B.G. Heo. 2017. Survey analysis of regional name, use and availability of Gnaphalium affine at Jeonnam province. People Plants Environ. 20(2):185-193. DOI: 10.11628/ksppe.2017.20.2.185

Sugimura, K. 2002. Present conservation status of Echinops setifer Iljin and its perspective. Japanese J. Conserv. Ecol. 6(2):143-154.

Won, S.I., S.H. Cho, R.W. Chung, Y.J. Chol, E.M. Kim, G.H. Cha, H.S. Kim, and H.G. Lee. 2008. A literature review on Tteoks, Korean rice cakes prior to the 17th century. Korean J. Food Cook. Sci. 24(4):419-430. 